\title{
KUALITAS DIGITALISASI HADIS: ANALISIS SWOT PADA APLIKASI ODOH
}

\author{
A. Darussalam \\ Jurusan Ilmu Hadis (ILHA) \\ Fakultas Ushuluddin dan Filsafat UIN Alauddin \\ E-mail: andidarus59@gmail.com
}

\section{Abstrak}

Facing the digital era and industrial revolution 4.0, the development of the quantity and quality of information services, especially in the development of hadith science in Indonesia is expected to increase significantly in order to reach all communities, especially for people who live in 3T (Terdepan, Tertinggal, Terluar). However, at present the quantity and quality of information technology in the development of hadith science in Indonesia has not been satisfactory, especially by people living in the 3T area. This research, trying to answer the challenges through a SWOT analysis of the One Day One Hadith (ODOH) application on the Android operating system. The results of the study show that there are advantages and opportunities that are owned, but there are some weaknesses and threats to be followed up as early as possible in advancing literacy and understanding of Islam, especially in the science of hadith to Muslims in Indonesia..

\section{Keywords}

hadith science, information technology, digital era

\section{Pendahuluan}

Pesatnya perkembangan ilmu pengetahuan dan teknologi di era digital saat ini telah mempengaruhi pola perilaku manusia dalam mengakses berbagai informasi dan berbagai fitur layanan elektronik. Salah satu perkembangan teknologi terkini di Indonesia adalah Information Technologies 
(IT) di berbagai hal dan telah mengalami perkembangan yang cukup pesat dan menyebabkan sejumlah perubahan besar bagi masyarakat. Marshall Mcluhan yang dikutip oleh Yusuf Hadi mengungkapkan bagaimana medium, atau proses teknologi di zaman kita, membentuk dan menata ulang pola saling ketergantungan sosial dan semua aspek kehidupan pribadi kita. Dia telah memaksa kita untuk mempertimbangkan dan menilai kembali hampir semua pemikiran, tindakan, dan institusi yang sebelumnya kita anggap sudah mapan. ${ }^{1}$

Secara umum, perkembangan zaman informasi mencirikan karakteristik berikut: a) meningkatkan kapasitas untuk mengumpulkan, menyimpan, memanipulasi, dan menyajikan informasi; b) kecepatan di mana informasi disajikan meningkat; c) miniaturisasi perangkat keras; d) keragaman pilihan informasi untuk melayani berbagai kebutuhan; e) biaya perolehan informasi, terutama biaya untuk pengiriman data cepat jarak jauh, yang relatif menurun; f) kemudahan penggunaan produk teknologi informasi dan komunikasi, baik dalam bentuk perangkat keras maupun perangkat lunak; g) kemampuan untuk mendistribusikan informasi lebih cepat dan lebih luas, dan karena itu informasi lebih mudah diperoleh, dengan menembus batas geografis; dan h) meningkatkan manfaat informasi dengan keragaman layanan yang dapat disediakan, memungkinkan solusi yang lebih baik untuk masalah yang ada dan membuat prediksi masa depan yang lebih cepat. ${ }^{2}$ Pengembangan teknologi informasi dan komunikasi ini menunjukkan bahwa era TI telah mengalami masa depan yang lebih praktis, efisien dan kreatif.

\footnotetext{
1 Yusufhadi Miarso, Menyemai Benih Teknologi Pendidikan, (Jakarta: Kencana, 2011), h. 491.

2 Yusufhadi Miarso, Menyemai, h. 488.
}

TAHDIS Volume 10 Nomor 1 Tahun 2019 
Purwanto menyatakan bahwa pesatnya perkembangan TI telah mempengaruhi berbagai aspek kehidupan manusia, termasuk bidang pendidikan. Perkembangan teknologi pendidikan tidak lepas dari perubahan yang terjadi di bidang teknologi dan di bidang pendidikan. Teknologi informasi kini telah mengalami perkembangan luar biasa, seperti portofolio elektronik, permainan dan simulasi komputer, buku digital (ebook), teknologi nirkabel, dan komputasi mobile. ${ }^{3}$

Mayoritas umat Islam sepakat bahwa hadis Nabi adalah salah satu sumber ajaran Islam, tepatnya sumber ajaran Islam kedua 4 . Secara terminologis, kata hadìs berarti segala sabda, perbuatan, taqrìr dan hal-ihwal yang disandarkan kepada Nabi Muhammad $^{5}$. Sebagai sumber ajaran Islam, itu adalah referensi bagi setiap Muslim dalam mempraktikkan agama, termasuk untuk mengatasi semua masalah kehidupan yang sedang dihadapi oleh manusia. Dengan demikian, secara teoritis, hadis Nabi memiliki makna universal, sàlih li kulli zamàn wa makàn (cocok untuk semua waktu dan tempat).

Mengingat pentingnya penerapan teknologi informasi serta kemuliaan mempelajari hadis yang menjadi sumber utama kedua setelah al-Qur'an, peneliti tertarik mengembangkannya lebih lanjut. Penelitian yang mengkaji perkembangan ilmu hadis dan hubungannya dengan teknologi informasi, khususnya dalam sistem operasi android pada

3 Purwanto, Jejak Langkah Perkembangan Teknologi Pendidikan di Indonesia, (Jakarta: Pustekkom-Depdiknas, 2005), h. 10.

4 Kehujjahan hadith sebagai sumber ajaran Islam kedua ini dapat ditemukan uraiannya secara detail dalam karya-karya Usùl Fiqh. Lihat misalnya al-Shatibi, al-Muwàfaqàt fì Usùl al-Sharì'ah, (Beirut: Dar alMa'rifah, 1997), Jl. II, h. 389-460; Wahbah al-Zuhaili, Usùl al-Fiqh al-Islàmì, (Beirut: Dar al-Fikr al-Mu'aêir, 2001), Jl. I, h. 458-460; dan al-Amidi, alIhkàm fi Usùl al-Ahkàm, (Beirut: Dar al-Fikr, 1996), Jl. I, h.112-137.

5 M. 'Ajjaj al-Khatib, Usùl al-Hadith 'Ulùmuhu wa Musthalahuh, (Beirut: Dar al-Fikr, 1989), h. 25.

TAHDIS Volume 10 Nomor 1 Tahun 2019 
smartphone bisa dikatakan masih jarang (Juni, 2019). Aplikasi One day One Hadis (selanjutnya disingkat ODOH) merupakan hasil luaran oleh Pusat kajian Hadis (PKH) yang berlokasi di Jakarta dan telah didownload lebih 100.000 kali di play store, sehingga aplikasi ini dapat dijadikan salah satu sample aplikasi kajian hadis yang cukup diminati dan kejelasan sumber (PKH). Penelitian ini diharapkan bisa menjadi bahan rekomendasi bagi pendidik dan pemerhati pendidikan ilmu hadis di Indonesia untuk meningkatkan kualitas kajian hadis di Indonesia melalui penerapan teknologi informasi yang modern. Penelitian ini menggunakan analisis data kualitatif untuk menganalisis persepsi pengguna mengenai kualitas layanan aplikasi One day One Hadis (ODOH- Satu Hari Satu Hadis), maka rumusan masalah yang dapat diangkat adalah, "bagaimana kualitas layanan aplikasi One day One Hadis (ODOH) dengan menggunakan analisis SWOT?".

\section{Tinjauan Pustaka Definisi Analisis SWOT}

Perencanaan strategis memiliki peran penting dalam merumuskan ide pada organisasi/perusahaan, mengarahkan kegiatan organisasi di masa depan, dan meningkatkan kinerja6. Perencanaan strategis sering melibatkan beberapa langkah, salah satunya adalah memeriksa lingkungan organisasi. Analisis SWOT telah dinilai sebagai alat yang paling sering digunakan untuk menganalisis lingkungan organisasi ${ }^{8}$. Ini

${ }^{6}$ Greenley, G. E. Strategic planning and company performance: An appraisal of the empirical evidence.Scandinaia, (t.tp: Journal of Management,10 (4), 1994), h. 383-396.

7 Weihrich, H. The TOWS matrix-A tool for situational analysis.(t.tp: Long Range Planning, 15(2),1982), h. 54-66.

8 Glaister, K. W., \& Falshaw, J. R. Strategic planning: Still going strong? (t.tp: Long Range Planning,32(1), 1999), h. 107-116.

TAHDIS Volume 10 Nomor 1 Tahun 2019 
adalah alat analitik sederhana dan menyeluruh ${ }^{9}$ untuk memeriksa kekuatan, kelemahan, peluang, dan ancaman yang terkait dengan organisasi ${ }^{10}$. Atau dengan kata lain, S-W-O-T digunakan untuk menilai kekuatan dan kelemahan sumber daya organisasi dan peluang serta tantangan eksternal. Menurut David semua organisasi memiliki kekuatan dan kelemahan dalam bidang fungsional organisasi, yang dapat digunakan sebagai dasar untuk tujuan dan penentuan strategi organisasi11. Dengan demikian, analisis SWOT merupakan instrumen yang berguna dalam menganalisa strategi ${ }^{12}$, dalam konteks artikel ini ditujukan untuk menilai kualitas layanan aplikasi ODOH, sehingga diharapkan dapat meminimalkan kelemahan pada aplikasi dan meminimalkan dampak ancaman yang timbul dan harus diatasi sedini mungkin. Melalui mengidentifikasi kekuatan dan kelemahan sebagai hasil dari analisis internal, peluang dan ancaman sebagai akibat dari lingkungan, organisasi dapat membangun strategi yang mengandalkan kekuatan untuk mengurangi kelemahan yang dirasakan, memanfaatkan peluang yang teridentifikasi dan menentukan rencana tindakan untuk mengurangi atau menghilangkan dampak ancaman ${ }^{13}$.

9 Kotler, P., dan G. Armstrong. Prinsip-prinsip pemasaran jilid 1. (Jakarta: Penerbit Erlangga, 2008), h. 214.

${ }^{10}$ Hung, K. 'Understanding China's Hotel Industry: A SWOT Analysis Understanding China's Hotel Industry: A SWOT Analysis', (t.tp: Journal of China Tourism Research, 9, 2013), h. 81-93.

11 David, F. R. Manajemen strategis. Edisi ke Sepuluh, (Jakarta: Penerbit Salemba Empat, 2006), h. 18.

12 Osita, I. C. 'Organization's stability and productivity: the role of SWOT analysis an acronym for strength, weakness, opportunities and threat', (t.tp: International Journal of Innovative and Applied Research, Volume 2, Issue (9), 2014), h. 23-32.

13 Živkovi, Ž. et al. 'Analytical Network Process in the Framework of SWOT Analysis for Strategic Decision Making (Case Study: Technical Faculty in Bor, University of Belgrade, Serbia)', (t.tp: Acta Polytechnica Hungarica. 12(7), 2015), h. 199-216.

TAHDIS Volume 10 Nomor 1 Tahun 2019 


\section{Teknologi Informasi dan Android}

Teknologi yang berasal dari bahasa Yunani, yaitu "technologia" menurut Webster's Dictionary berarti perawatan sistematis atau penanganan sesuatu secara sistematis, sedangkan "techne" sebagai dasar kata teknologi berarti, keterampilan, pengetahuan atau keahlian, keterampilan, pengetahuan. Sedangkan "informasi" adalah fakta atau apapun yang dapat digunakan sebagai input dalam menghasilkan informasi. ${ }^{14}$

Teknologi informasi juga berarti fasilitas dan infrastruktur sistem (hardware, software, useware), dan metode untuk memperoleh, mengirim, memproses, menafsirkan, menyimpan, mengelola, dan menggunakan data dengan cara yang bermakna. Oleh karena itu, teknologi informasi memberikan begitu banyak kemudahan dalam mengelola informasi dalam arti menyimpan, mengambil, dan memperbarui informasi. ${ }^{15}$ Jadi teknologi informasi adalah informasi yang diproses oleh teknologi untuk membuat informasi mudah disampaikan melalui teknologi seperti pemrosesan pesan atau informasi sehingga ada kemudahan dalam menerima dan menyampaikan pesan melalui teknologi.

Andorid adalah sistem operasi yang biasanya dipakai pada smartphone dan tablet ${ }^{16}$. Sistem operasi dapat diilustrasikan sebagai 'jembatan' antara perangkat (device) dengan pengguna, sehingga pengguna dapat berinteraksi dengan perangkat mereka dan menjalankan aplikasi yang

14 Rusman, Deni Kurniawan dkk, Pembelajaran Berbasis Teknologi Informasi dan Komunikasi: Mengembangkan Profesionalitas Guru, (Jakarta: Rajawali Pers, 2013), h. 78.

15 Bambang Warsita, Teknologi Pembelajaran, landasan dan aplikasinya, (Jakarta: Rineka Cipta, 2008), h. 135.

16 Satyaputra, Alfa \& Maulina Eva Aritonang. Let's Build Your Android Apps With Android Studio. (Jakarta : PT Elex Media Komputindo, 2016). h. 2.

TAHDIS Volume 10 Nomor 1 Tahun 2019 
tersedia di perangkat. Sementara itu, menurut Nazrudin Safaat H dalam M. Ichwan, Fifin Hakiky ${ }^{17}$, Android adalah sistem operasi untuk perangkat seluler berbasis Linux yang mencakup sistem operasi, middleware, dan aplikasi. Android adalah sistem operasi untuk telepon seluler berbasis linux. Android menyediakan platform terbuka bagi pengembang untuk membuat aplikasi mereka sendiri. Selanjutnya Murtiwiyati \& Glenn Lauren ${ }^{18}$, Android adalah sistem operasi untuk perangkat seluler berbasis Linux yang mencakup sistem operasi, middleware dan aplikasi.

\section{Kualitas Layanan}

Dilihat dari definisinya, "kualitas" adalah kondisi dinamis yang mempengaruhi produk, layanan, orang, proses dan lingkungan yang memenuhi atau melampaui harapan ${ }^{19}$. Sedangkan definisi "pelayanan” menurut Kotler adalah setiap tindakan atau kegiatan yang dapat ditawarkan oleh pihak ke pihak lain, yang pada dasarnya tidak berwujud dan tidak mengakibatkan kepemilikan apapun ${ }^{20}$. Maksud dari kualitas pelayanan dapat didefinisikan sebagai usaha untuk memenuhi kebutuhan/keinginan konsumen dalam keseimbangan harapan

17 M. Ichwan \& Fifin Hakiky. Pengukuran Kinerja Goodreads Application Programming Interface (Api) Pada Aplikasi Mobile Android. (t.tp: Jurnal Informatika. Vol 2 (No 2), 2011) h.13-21.

18 Murtiwiyati \& Glenn Lauren. Rancang Bangun Aplikasi Pembelajaran Budaya Indonesia Untuk Anak Sekolah Dasar Berbasis Android. (t.tp: Jurnal Ilmiah Komputasi. Vol 12 (No 2), 2013), h. 2.

19 Tjiptono, F. Strategi pemasaran. Edisi ke Satu, (Yogyakarta: Penerbit Andi Offse, 2001), h. 71.

20 Kotler, P. Manajemen pemasaran di indonesia: Analisis, perencanaan, implementasi dan pengendalian. Jakarta: Penerbit Salemba Empat, 2002), h. 8.

TAHDIS Volume 10 Nomor 1 Tahun 2019 
dari konsumen 21 . Atau dengan pernyataan lain, pengertian kualitas layanan sesuatu yang harus dilakukan dengan baik ${ }^{22}$.

Berdasarkan definisi di atas, kajian kualitas layanan pada aplikasi ODOH, dapat diketahui dengan membandingkan persepsi pengguna terhadap layanan yang mereka terima, sesuai dengan standar kualitas layanan aplikasi yang mengacu pada penggunanya. Artinya, jika layanan aplikasi diterima atau dirasakan oleh pengguna sesuai dengan apa yang diharapkan, maka kualitas pelayanan dirasakan baik atau berkualitas tinggi. Sebaliknya, jika tingkat pelayanan yang diterima oleh pengguna lebih rendah dari yang diharapkan, maka kualitas layanan fdapat dirasakan buruk atau rendah kualitasnya. Dengan demikian, persepsi yang ditunjukkan oleh pengguna akan mempengaruhi loyalitas mereka dan akan menyampaikan persepsi kepada pengguna lainnya. Ini berarti bahwa persepsi yang ditunjukkan oleh pengguna secara langsung akan mempengaruhi loyalitas pengguna ${ }^{23}$.

Pengguna cenderung bersedia berbagi pengalaman positif mereka dengan orang lain $^{24}$ dan penilaian kualitas layanan dapat diamati berdasarkan dimensi kualitas layanan atau biasa disebut kualitas layanan. Kualitas pelayanan merupakan salah satu faktor utama yang telah mempengaruhi

21 Tjiptono, F. Strategi pemasaran... h. 73.

22 Supranto, J. Pengukuran tingkat kepuasan pelanggan. Cetakan ke Tiga, (Jakarta: Penerbit Rineka Cipta, 2006), h. 233.

${ }^{23}$ Nursiana, A. Pengaruh internet banking, kualitas layanan, reputasi produk, lokasi, terhadap loyalitas nasabah dengan intermediasi kepuasan nasabah. (t.tp: Jurnal Keuangan dan Perbankan 19 (3), 2015), h. 450-462.

24 Tobing, Fathorazzi, \& Wulandari. Model inovasi sistem pemasaran perbankan syariah berbasis floating market untuk penciptaan daya saing (model of islamic banking marketing innovation systems based on floating market for creation competitiveness). (t.tp: Jurnal Keuangan dan Perbankan 20 (1): 2016), h. 75-83.

TAHDIS Volume 10 Nomor 1 Tahun 2019 
kepuasan pengguna, hal ini sangat diperlukan untuk menjaga loyalitas pengguna.

\section{TUJUAN DAN MANFAAT}

\section{Tujuan Penelitian}

Berdasarkan permasalahan di atas, maka tujuan penelitian ini yaitu:

1. Untuk menganalisis kekuatan/kelebihan layanan aplikasi ODOH dari perspektif informasi pengguna.

2. Untuk menganalisis kelemahan layanan aplikasi ODOH dari perspektif informasi pengguna.

3. Untuk menganalisis peluang layanan aplikasi ODOH dari perspektif informasi pengguna.

4. Untuk menganalisis ancaman dan tantangan layanan aplikasi ODOH dari perspektif informasi pengguna.

\section{Manfaat Penelitian}

Dari penelitian ini diharapkan akan memberikan kegunaan sebagai berikut:

1. Bagi peneliti, penelitian ini merupakan suatu tahapan pembelajaran dalam menerapkan dan mengembangkan ilmu hadis 4.0, terutama yang berkaitan dengan penerapan keilmuan hadis dalam teknologi informasi, banyak saran dan kritik dari pengguna membuat peneliti tertantang meneliti lebih dalam bagaimana teknologi informasi dapat mempercepat dan menumbuhkan kesadaran kepada masyarakat akan nilai ajaran Islam khususnya dalam mempelajari ilmu hadis.

2. Bagi aplikator (perancang) aplikasi ODOH, hasil penelitian ini diharapkan dapat memberikan informasi strategis terkait kekuatan, kelemahan, peluang dan ancaman (SWOT) dari 
penerapan layanan aplikasi ODOH oleh pengguna, agar di kemudian hari menjadikan aplikasi ini yang lebih baik dan menjawab harapan pengguna.

\section{Metode Penelitian}

Metode penelitian yang digunakan dalam menulis artikel ini adalah deskriptif kualitatif. Penelitian deskriptif kualitatif dimaksudkan untuk mengumpulkan informasi aktual dan terperinci, mengidentifikasi masalah, membuat perbandingan atau evaluasi, dan menentukan apa yang dilakukan orang lain dalam menghadapi masalah dan pembelajaran serupa dari pengalaman mereka untuk menentukan rencana dan keputusan di masa depan ${ }^{25}$. Dengan demikian, penelitian deskriptif kualitatif hanya untuk menggambarkan respons terhadap suatu situasi atau peristiwa, sehingga tidak menjelaskan hubungan kausalitas dan untuk menguji hipotesis.

Objek penelitian adalah persepsi informan mengenai aspek penggunaan aplikasi ODOH yang berkaitan tentang kelebihan, kekurangan, peluang serta ancaman atau kerawanan (SWOT) dalam aplikasi ODOH. Data dikumpulkan melalui wawancara 10 informan dari pengguna yang menggunakan aplikasi ODOH yang dimanfaatkan atau diamati selama periode 1 hingga 25 Juli 2019.

25 Suyanto, B., dan Sutinah. Metode penelitian sosial. (Jakarta: PT Kencana Persada, 2006), h. 3-4

TAHDIS Volume 10 Nomor 1 Tahun 2019 


\section{Tabel 3}

\begin{tabular}{|c|c|l|l|}
\hline INFORMAN & P/W & \multicolumn{1}{|c|}{ PEKERJAAN } & \multicolumn{1}{|c|}{ LAMA } \\
PENGGUNAAN
\end{tabular}

\section{Teknik Pengumpulan Data}

Data yang dikumpulkan melalui metode wawancara mendalam, untuk menerima gambaran terkait kualitas layanan aplikasi ODOH yang dirasakan informan. Wawancara dengan pertanyaan terbuka yang memungkinkan saat wawancara berlangsung muncul pertanyaan lain untuk memperdalam jawaban informan.

\section{Teknik Analisis Data}

Data yang terkumpul pasca wawancara dilakukan reduksi data dengan cara memilih dan memilah hasil wawancara yang sesuai dengan tujuan pokok penelitian, setelah reduksi data dilakukanlah display data yaitu mengelompokkan hasil wawancara berdasar variabel yang diteliti, lalu penarikan kesimpulan dengan menggunakan 
metodologi komparatif konstan ${ }^{26}$. Metodologi komparatif konstan menerapkan logika induktif, intuitif dan interpretasi, tujuannya untuk membandingkan dan menemukan hubungan antar kejadian sepanjang penelitian ${ }^{27}$. Pengambilan kesimpulan seperti tujuan penelitian ini ialah mendalami persepsi pengguna mengenai kualitas layanan aplikasi ODOH dan faktor yang mendasarinya.

\section{HASIL DAN LUARAN YANG DICAPAI}

\section{Analisis SWOT}

\section{Strength Analysis}

Hasil wawancara dengan pengguna memunculkan beberapa kekuatan dalam layanan aplikasi, pertama adalah kesempatan revolusi industri 4.0 memungkinkan kemajuan fasilitas teknologi informasi di sektor keilmuan dan secara tidak langsung akan memajukan umat Muslim khususnya yang berada di daerah 3T (Terdepan, Terluar dan Tertinggal) yang jauh dari perkotaan,

Kedua, gerakan membaca hadis tidak sekuat gerakan membaca Al-Qur'an yang sudah intens di Indonesia, padahal hadis adalah sumber agama kedua setelah Al-Qur'an. Pusat Kajian Hadis (PKH) menyadari hal ini dan membuat program/aplikasi hadis dengan moto: yang mudah, sederhana

26 Teknik analisis komparatif adalah teknik yang digunakan untuk membandingkan kejadian-kejadian yang terjadi disaat peneliti menganalisa kejadian tersebut dan dilakukan secara terus menerus sepanjang penelitian dilakukan. Berney G. Galaser dan Anselm L. Strouss mengemukakan beberapa Teknik Komparatif Konstan, yaitu: membandingkan kejadian yang dapat diterapkan pada tiap kategori, tahap memadukan kategori-kategori serta ciri-cirinya, tahap membatasi lingkup teori dan tahap menulis teori, diakses 20 Juli 2019 ( http://laurensiusaditya.blogspot.com)

27 Offstein E.H., M.B Larson, A.L McNeil, \& H.M Mwale. Are We Doing Enough for Today's Graduate Students? (t.tp: The International Journal of Educational Management, 18(7), 2004), h. 396-407.

TAHDIS Volume 10 Nomor 1 Tahun 2019 
dan menarik, cocok untuk semua kelompok. Aplikasi One Day One Hadith $(\mathrm{ODOH})$ cukup memudahkan masyarakat dalam merutinkan membaca hadis Nabi kapan saja dan di mana saja (mobility), cukup mempunyai handphone (Android) dan internet, memungkinkan menjangkau kelompok masyarakat yang tidak terlayani oleh akses pustaka keilmuan seperti toko buku, perpustakaan universitas dan akses lainnya yang biasanya mudah didapatkan di perkotaan.

Ketiga, ODOH berasal dari hadis sahih, penulis memilih hadis yang sederhana dan menarik, yang semuanya berasal dari Sahih Bukhari, buku yang dikatakan oleh Imam Shafi'i adalah buku paling indah kedua setelah Al-Qur'an di setiap hari, pengguna akan dikirimi pemberitahuan yang memberikan gambaran umum tentang hadis hari itu. Dengan tema hadis yang berbeda setiap bulan, pengguna akan belajar hadis dengan mudah, dan tanpa melelahkan pengguna dapat belajar 354 hadis dalam setahun. Aplikasi ini diharapkan menyampaikan "pesan" dan intisari dari hadis, karena di dalamnya berisi banyak hadis sahih yang dapat memperkuat amal, iman serta mengenal hadis Rasul lebih dalam. Keempat, aplikasi ODOH dapat menghemat waktu pengguna dalam mempelajari hadis, disebabkan lembaga pendidikan (hadis) dapat berkolaborasi dengan penyedia jasa teknologi informasi dalam menjalankan dan mendakwahkan ilmu hadis kepada masyarakat dimanapun mereka berada.

Kelima, akses layanan referensi hadis cukup banyak, hal ini akan berbeda jika dilakukan dengan cara konvensional, yakni membawa buku cetak di tangan, tentu bagi sebagian orang agak kewalahan membawa buku yang cenderung tebal kemana-mana, berbeda dengan hanya membawa satu HP yang sudah memuat ratusan hadis di dalamnya. Keenam, varian fitur layanan yang cukup dan dapat dimanfaatkan oleh masyarakat, 
meski belum banyak dimaksimalkan oleh penggunanya. Ketujuh, institusi pendidikan seperti Pusat Pengkajian Hadis (PPH) dapat menjadi pengaman kevalidan informasi hadis dan apa yang ada di dalam aplikasi tersebut, dimana bisa saja pengguna yang masih awam kiranya khawatir terhadap informasi yang bisa saja keliru.

Kedelapan, segala proses sistem yang ada di aplikasi ODOH berlandaskan nilai Islam dan melarang aktivitas yang dilarang Islam. Selain itu tampilannya cukup rapih, sehingga memudahkan pengguna dalam berinteraksi. Berikut informasi singkat fitur $\mathrm{ODOH}$ :

a. Info Hadis harian, yakni hadis-hadis pilihan yang menarik dan mudah, semua bersumber dari Shahih Bukhari. Notifikasi setiap hari, sebagai pengingat untuk membuka hadis hari itu.

b. Kalender Hijriyah, yaitu Aplikasi berisi kalender hijriyah, dengan tema baru yang diperbaharui setiap bulannya.

\section{Weakness Analysis}

Kelebihan yang dimiliki aplkasi ODOH tentu masih ada hal yang perlu ditingkatkan, beberapa kelemahan hasil wawancara dengan pengguna diantaranya, pertama ialah ketimpangan infrastruktur teknologi informasi yang belum merata antar daerah khususnya kepada daerah 3T, menyebabkan masyarakat cukup kesulitan mengaksesnya (misal: kelambatan akses berujung gagalnya membuka aplikasi), sehingga layanan belum dirasakan optimal. Kedua, timbulnya aksi kejahatan, seperti pembobolan aplikasi dan mengubah data menjadi tidak akurat atau keliru, membuat masyarakat sedikit ragu untuk menerima info yang ada di dalam aplikasi, sehingga tidak sedikit dari mereka tetap berharap adanya perpustakaan kajian 
Islami (offline) hadir di daerah mereka, sehingga lebih valid dalam mengakses ilmu.

Ketiga, institusi atau kelompok kajian kelimuan hadis yang bekerja sama dengan penyedia teknologi informasi belum tentu memiliki lisensi secara tersistem dan legal, sehingga dimungkinkan terjadi praktik penyalahgunaan wewenang atau penyimpangan yang justru dapat merugikan lembaga institusi itu sendiri. Keempat, pengetahuan masyarakat terkait teknologi informasi yang relatif rendah memungkinkan mereka belum dapat maksimal dalam mengakses $\mathrm{ODOH}$, sehingga peran dari Dai, Guru, lembaga pendidikan dan lainnya sangat dibutuhkan dalam sosialisasi dan edukasi penggunaan teknologi informasi berbasis android yang aman. Kekhawatiran ini, rerata disebabkan berasal dari generasi baby boomers (kelahiran 1960 ke bawah) yang belum familiar akan dunia digital. Kelima, dengan beragam smartphone yang dimiliki (merek dan spesifikasi) pengguna terkadang mengeluhkan akan kerumitan mengakses $\mathrm{ODOH}$, aplikasi sering error, terkadang sering force close sendiri.

Keenam, belum adanya fitur tanya-jawab antar pengguna dan pihak aplikator $\mathrm{ODOH}$, fitur tersebut dapat membuat pengguna memperluas pemahaman hadis yang dikaji. Aspek fitur tanya-jawab merupakan harapan pengguna yang berkaitan dengan kecepatan aplikasi merespons dan melayani pengguna, yang terlihat dari manfaat dan kualitas interaksi. Ketujuh, alangkah lebih baik dan bermanfaat apabila diberi penjelasan lebih lanjut syarah hadis (seperti Fathul Bari), asbabul wurud, poin-poin simpulan, kandungan/makna, atau lainnya yang bisa memudahkan pengguna aplikasi hadis ini untuk belajar, mengambil pelajaran, dan mempraktikkan/menerapkan langsung kandungan dari hadis tersebut. Kedelapan, salah satu informan yang menemukan 
adanya hadis syiah imam dua belas, sehingga memberikan warning ketika menginstall dan mengakses aplikasi ini, meski pihak aplikator $\mathrm{ODOH}$ sudah menginfokan sejak awal bahwa hadis di dalam aplikasi berasal dari hadis sahih bukhari. Selain itu, salah satu informan menemukan adanya arti hadis yang keliru fatal (beda subjek dan objek), sehingga pengguna lainnya juga dipersilahkan untuk tetap kritis dan melaporkan kepada aplikator ODOH agar segera direvisi.

Kesembilan, beberapa saran fitur layanan yang menurut pengguna perlu dimaksimalkan diantaranya: a) menambahkan widget dan jadwal sholat; b) terkadang fitur kalender keliru dalam memberikan informasi yang sesuai; c) kitab hadis bisa lebih variatif, tidak hanya H.R Bukhari tapi juga dari yang lain (seperti kutub al-tis'ah); d) memuat bahasa lainnya seperti bahasa inggris, melayu dan lainnya agar bisa dibagikan dan diakses ke teman/pengguna di luar Indonesia; e) halaman konten hadis dapat lebih diperluas agar lebih menarik dan nyaman saat membacanya, tidak lagi membutuhkan terlalu banyak scroll-nya.

\section{Opportunity Analysis}

Hasil wawancara menunjukkan beberapa peluang, pertama ialah revolusi industri 4.0 masuk dalam berbagai sektor, termasuk dalam institusi keilmuan, kesadaran masyarakat perlahan mulai tumbuh untuk lebih banyak memanfaatkan teknologi informasi yang valid, karena dianggap lebih mudah, aman dan nyaman (mobility) dalam mengaksesnya, dibanding harus ke perpustakaan atau membawa buku yang cukup berat. Kedua, peluang besar dalam digitalisasi keilmuan, menuntut pemerintah dan pemerhati pendidikan memajukan serta mengawasi peran teknologi informasi dan percepatan pemahaman agama masarakat, 
sehingga dapat memaksimalkan dakwah Islam ke seluruh elemen masyarakat, serta meminimalisir kekhawatiran masyarakat dalam menggunakan layanan teknologi informasi.

Ketiga, fasilitas fitur komunikasi tanya-jawab dengan pihak aplikator ODOH diharapkan pengguna agar dapat memperoleh kejelasan dari hadis atau info yang ditampilkan di aplikasi. Keempat, desain konten hadis diharapkan lebih luas tampilannya, menarik dan memudahkan sehingga pengguna tetap loyal dalam penggunaan aplikasi. Kelima, adanya edukasi bagi pengguna yang belum familiar menggunakan teknologi informasi berbasis android dalam aplikasi ODOH. Keenam, infrastruktur IT yang mumpuni dapat memaksimalkan akses layanan seperti kecepatan proses fitur, semakin cepat aksesnya, semakin pengguna merasakan kemudahan menggunakannya, karena konsumen dapat menghemat waktunya.

Ketujuh, kompetisi dan kemajuan industri 4.0 memunculkan kompetisi dan kolaborasi dalam berbagai bidang, prosedur dan prinsip tanggung jawab yang melibatkan semua proses atas interaksi masyarakat/pengguna dan aplikator $\mathrm{ODOH}$, dalam memaksimalkan aplikasi ODOH dalam memberikan manfaat kepada masyarakat. Kedelapan, SDM dalam bidang IT dan komunikasi cukup dibutuhkan para pemerhati pendidikan, keandalan IT dirasakan dengan kemudahan akses sedangkan kemampuan komunikasi dapat memudahkan analisis fitur dan interaksi dengan pengguna.

\section{Threats Analysis}

Beberapa informasi terkait ancaman atau kekhawatiran pada aplikasi ODOH. Pertama, kemajuan teknologi yang semakin canggih, tanpa disertai peningkatan kualitas sumber daya manusia yang mumpuni (tekonologi informasi dan analisis 
konten), akan menjadi ketimpangan dalam melayani masyarakat (pengguna). Kedua, globalisasi dan keterbukaan memungkinkan aplikasi asing dengan kemajuan teknologi dan analisis konten yang mungkin lebih canggih dan menarik, dapat memudahkan atau bisa menyulitkan masyarakat dalam memperoleh kevalidan informasi yang bermanfaat. Ketiga, lingkungan politik suatu negara cukup berpengaruh dalam penyebaran informasi khususnya pemahaman agama, seperti Cina yang membatasi akses internet yang berasal dari luar dan dalam negeri, sehingga pemerhati pendidikan diharapkan menyiapkan strategi dalam memberikan pelayanan terhadap masyarakat.

Keempat, pembobolan data aplikasi atau pengguna, baik oleh internal maupun eksternal. Perlindungan data bertujuan melindungi aplikator dan pengguna dari kebocoran dan gangguan data pribadi. Kelima, selain dari sistem keamanan dalam layanan aplikasi $\mathrm{ODOH}$, diperlukan juga edukasi pengamanan penggunaan smartphone, seperti tidak memberikan akses username dan password kepada orang lain sehingga beresiko hilangnya data dalam smartphone dan hal lain yang disebabkan kelalaian dari pengguna sendiri. Oleh karenanya, derajat keluhan pengguna atas masalah keamanan yang dialami merupakan indikator penting untuk mengenali seberapa jauh masalah dan gangguan keamanan dirasakan. Keenam, infrastruktur IT juga dikhawatirkan berpengaruh terhadap performa layanan akses ke aplikasi, karena jaminan kestabilan dan keamanan menciptakan kenyamanan pada pengguna. 


\section{E. Penutup}

Sebagai sebuah kesimpulan, aplikasi ODOH sudah cukup baik dan bermanfaat, sehingga dapat menjangkau masyarakat daerah 3T (Terdepan, Terpencil dan Terluar) dalam memberikan edukasi keilmuan hadis. Analisis SWOT di atas menunjukkan gambaran bagaimana teknologi informasi telah jauh berkembang memberikan manfaat kepada masyarakat, dengan layanan aplikasi ODOH pada sistem operasi android, pengguna dapat meningkatkan efektivitas dan efisiensi dalam mengenal ilmu agama, khususnya ilmu hadis. Globalisasi akan tetap terjadi dan tidak untuk dihindari, aplikasi ODOH dibanding dengan aplikasi sejenis lainnya, khususnya yang berasal dari luar negeri, sepertinya masih cukup banyak tertinggal dan masih perlu dibenahi. Penerapan teknologi informasi dalam perkembangan ilmu hadis pada aplikasi ODOH memiliki kelebihan, akan tetapi masih belum semua masyarakat Indonesia dapat memaksimalkannya, baik dari segi kualitas dan kuantitas, apalagi Indonesia dikenal sebagai The Largest Muslim Country, oleh karena itu upaya dari pemerintah khususnya Kementrian Agama, Dai, Guru dan pemerhati Pendidikan (ilmu hadis) dalam sosialisasi dan edukasi ke masyarakat cukup urgent khususnya untuk menjangkau masyarakat 3T dengan kemajuan IT. Finally, tentu tiada gading yang tak retak, penelitian ini memiliki keterbatasan, oleh karenanya penelitian selanjutnya masih sangat terbuka, khususnya dalam mengembangkan teknologi informasi dan ilmu hadis. Wallahu A'lam bis Shawwab. 


\section{DAFTAR PUSTAKA}

Al-Amidi, al-Ihkàm fi Usùl al-Ahkàm, Beirut: Dar al-Fikr, 1996.

Bambang Warsita, Teknologi Pembelajaran, landasan dan aplikasinya, Jakarta: Rineka Cipta, 2008.

David, F. R. Manajemen strategis. Edisi ke Sepuluh,Jakarta: Penerbit Salemba Empat, 2006.

Glaister, K. W., \& Falshaw, J. R. Strategic planning: Still going strong? t.tp: Long Range Planning,32(1), 1999.

Greenley, G. E. Strategic planning and company performance: An appraisal of the empirical evidence.Scandinaia, t.tp: Journal of Management,10 (4), 1994.

Hung, K. 'Understanding China's Hotel Industry: A SWOT Analysis Understanding China's Hotel Industry: A SWOT Analysis', t.tp: Journal of China Tourism Research, 9, 2013.

Kotler, P. Manajemen pemasaran di indonesia: Analisis, perencanaan, implementasi dan pengendalian. Jakarta: Penerbit Salemba Empat, 2002.

Kotler, P., dan G. Armstrong. Prinsip-prinsip pemasaran jilid 1. Jakarta: Penerbit Erlangga, 2008.

M. 'Ajjaj al-Khatib, Usùl al-Hadìth 'Ulùmuhu wa Musthalahuh, Beirut: Dar al-Fikr, 1989.

M. Ichwan \& Fifin Hakiky. Pengukuran Kinerja Goodreads Application Programming Interface (Api) Pada Aplikasi Mobile Android.t.tp: Jurnal Informatika. Vol 2 (No 2), 2011.

Murtiwiyati \& Glenn Lauren. Rancang Bangun Aplikasi Pembelajaran Budaya Indonesia Untuk Anak Sekolah Dasar Berbasis Android. t.tp: Jurnal Ilmiah Komputasi. Vol 12 (No 2), 2013. 
Offstein E.H., M.B Larson, A.L McNeil, \& H.M Mwale. Are We Doing Enough for Today's Graduate Students?, t.tp: The International Journal of Educational Management, 18(7), 2004.

Osita, I. C. 'Organization's stability and productivity: the role of SWOT analysis an acronym for strength, weakness, opportunities and threat', (t.tp: International Journal of Innovative and Applied Research, Volume 2, Issue (9), 2014

Purwanto, Jejak Langkah Perkembangan Teknologi Pendidikan di Indonesia, Jakarta: Pustekkom-Depdiknas, 2005.

Rusman, Deni Kurniawan dkk, Pembelajaran Berbasis Teknologi Informasi dan Komunikasi: Mengembangkan Profesionalitas Guru, Jakarta: Rajawali Pers, 2013.

Satyaputra, Alfa \& Maulina Eva Aritonang. Let's Build Your Android Apps With Android Studio. Jakarta : PT Elex Media Komputindo, 2016.

al-Shatibi, al-Muwàfaqàt fi Usùl al-Sharì'ah, Beirut: Dar alMa'rifah, 1997.Supranto, J. Pengukuran tingkat kepuasan pengguna. Cetakan ke Tiga, Jakarta: Penerbit Rineka Cipta, 2006.

Suyanto, B., dan Sutinah. Metode penelitian sosial. Jakarta: PT Kencana Persada, 2006.

Tjiptono, F. Strategi pemasaran. Edisi ke Satu, Yogyakarta: Penerbit Andi Offse, 2001.

Wahbah al-Zuhaili, Usùl al-Fiqh al-Islàmì, Beirut: Dar al-Fikr alMu'aêir, 2001.

Weihrich, H. The TOWS matrix A tool for situational analysis.t.tp: Long Range Planning, 15(2),1982.

Yusufhadi Miarso, Menyemai Benih Teknologi Pendidikan, Jakarta: Kencana, 2011.

TAHDIS Volume 10 Nomor 1 Tahun 2019 
Živkovi, Ž. et al. 'Analytical Network Process in the Framework of SWOT Analysis for Strategic Decision Making (Case Study: Technical Faculty in Bor, University of Belgrade, Serbia)', t.tp: Acta Polytechnica Hungarica. 12(7), 2015 